so that the paragraph which states merely that colloidal magnetite has been examined, and the remarks on sea urchin eggs, may fulfil a useful purpose. The author expresses the hope that the book may contribute, however infinitesimally, to the labours of those scientific men who are seeking to parry the blows of an enemy. It may not do that; but it certainly will perform a valuable service in one small region of endeavour in helping to bridge the devastating gap which is being made by the war years.

E. C. Stoner. omitted. Section 3 deals with both ground and aerial surveying, and is necessarily selective. The last section, of about sixty pages, dealing with errors of surveying, contains a mass of information, the theoretical work being rather too concisely expressed, but with the applications fully explained by means of numerical examples.

Finally, it may be said that the production is excellent, and the publishers are to be congratulated on presenting so well, in war-time, this most useful and attractive text-book.

\title{
SURVEYING FOR STUDENTS
}

\section{Higher Surveying}

By Dr. Arthur Lovat Higgins. Pp. viii +463. (London: Macmillan and Co., Ltd., 1944.) 25s. net.

TrHAT Dr. A. L. Higgins is an enthusiast where $l$ the subject of surveying is concerned will be evident to readers of his latest book entitled "Higher Surveying". It is written on somewhat unorthodox lines, each section consisting of a number of "Articles" followed by a selection of examples.

Though ostensibly written for students, the book should have a much wider appeal. The articles are well written, and many of them are concise critical essays on appropriate surveying topics: they include many historical references and discuss modern developments. It may be that these scholarly outlines will sometimes be more appreciated by those who already have a good knowledge of surveying than by the student whose horizon is less wide. Even if not fully understood by the student, however, they will give him a broad view of the subject, into which later knowledge can be fitted.

The impression is given that Dr. Higgins had a great deal of trouble in deciding the scope of the book, and in fixing its title. In the first place, he had so much material that he decided to jettison much that was of a more elementary character, and also some details of field technique which the student might be expected to learn in the field. It probably seemed too drastic to carry out this policy rigidly, and opportunities have been taken in the text and examples to incorporate much that is not strictly 'higher surveying', but which completes and rounds off the treatment of other subject matter. Even with these omissions the author's troubles were not ended. He was anxious to include a considerable number of worked examples taken from university examination papers, and also others for the student to solve. Consequently, with the space at his disposal, he had either to omit subject matter he was anxious to include, or deal with it in a less detailed manner than he would have wished. In some cases the examples have been used, not to illustrate the text, but to supplement or even as a substitute for it. In other cases the text is somewhat too concise and condensed for easy reading. The reviewer considers that Dr. Higgins has overcome his difficulties very successfully, and the book cannot fail to be of great value to its readers.

The six main sections of the book deal respectively with (1) instruments, (2) engineering surveys, (3) photogrammetry, (4) field astronomy, (5) geodetical surveys and (6) errors in surveying.

These sub-titles sufficiently define the scope of the book. It is from the section on engineering surveys that much of the elementary work on chain surveying, traversing, levelling, plane-tabling, etc., has been

\section{THE STUDY OF FINE PARTICLES}

Determination of Particle Size in Sub-Sieve Range A Report of Discussions. Pp. 69. (London: British Colliery Owners' Research Association and the British Coal Utilisation Research Association, 1944.)

7 HE measurement of fine particles is a subject of increasing importance in many industrial processes and in the study of natural phenomena concerning soils and dusts. It is now realized that the influence of very fine particles is so predominant that in many researches measurements would be desirable to a lower limit of one micron in diameter, though it is not often that this degree of accuracy can be attained. The above report contains an account of the activities of two research associations having the object of improving particle size measurements, and they may be complimented on the broad way in which the problem has been treated.

The volume reports two informal conferences held to discuss the subject, with an introductory paper by Drs. Skinner and Boas-Traube and Messrs. Brown and Hawksley. This paper summarizes recent developments in the measurement of fine particles, dealing with microscopical measurement, the dispersion of various powders in liquids, and in considerable detail with the measurement of size distribution by determining the rate of change in optical density of a dilute suspension of the powder in a liquid. This latter method is now being extensively used both for research purposes and for the rapid checking of industrial products as a routine procedure. The report of the second conference expresses the views of research workers from various laboratories of the Department of Scientific and Industrial Research and a wide range of industrial organizations.

From this discussion it is apparent that the problem needing most urgent research is that of effectively dispersing a powder in a liquid, since this procedure is involved in almost all methods of sub-sieve particlesize determination. A large number of peptizing agents have been suggested for various powdered substances, but no general theory has yet been developed that would obviate the present method of proceeding by trial and error. Many processes and designs of apparatus are now available for measuring sub-sieve particles which are satisfactory for comparing the fineness of various powders, but serious discrepancies are shown to exist when the same powder is tested in different designs of apparatus. Thus it is evident that further research is necessary on many details before the absolute size distribution of the finest particles can be determined; but the report is a valuable guide to those engaged on particle-size measurement regarding the choice and most effective way of using such apparatus as is available.

H. Heywood. 